\title{
The Influence of Fetch on the Response of Surface Currents to Wind Studied by HF Ocean Surface Radar
}

\author{
YADAN MAO \\ School of Mathematics, Physics and IT, James Cook University, Townsville, Queensland, Australia \\ MALCOLM L. Heron \\ Marine Geophysical Laboratory, James Cook University, and AIMS@JCU, Townsville, Queensland, Australia
}

(Manuscript received 4 October 2006, in final form 5 October 2007)

\begin{abstract}
The momentum transfer from wind to sea generates surface currents through both the wind shear stress and the Stokes drift induced by waves. This paper addresses issues in the interpretation of HF radar measurements of surface currents and momentum transfer from air to sea. Surface current data over a 30-day period from HF ocean surface radar are used to study the response of surface currents to wind. Two periods of relatively constant wind are identified-one for the short-fetch condition and the other for the long-fetch condition. Results suggest that the ratio of surface current speed to wind speed is larger under the long-fetch condition, while the angle between the surface current vector and wind vector is larger under the short-fetch condition. Data analysis shows that the Stokes drift dominates the surface currents under the long-fetch condition when the sea state is more mature, while the Stokes drifts and Ekman-type currents play almost equally important roles in the total currents under the short-fetch condition. The ratios of Stokes drift to wind speed under these two fetch conditions are shown to agree well with results derived from the empirical wave growth function. These results suggest that fetch, and therefore sea state, significantly influences the total response of surface current to wind in both the magnitude and direction by variations in the significance of Stokes drift. Furthermore, this work provides observational evidence that surface currents measured by HF radar include Stokes drift. It demonstrates the potential of HF radar in addressing the issue of momentum transfer from air to sea under various environmental conditions.
\end{abstract}

\section{Introduction}

Ocean surface currents are dominant features that impact maritime industries as well as the monitoring of climate and weather. The surface currents are coupled to the atmosphere by wind stress and momentum transfer, and to the deep ocean by eddy viscosity and momentum transfer. The main physical processes that determine the speed and direction of currents at and near the surface are Stokes drift, resulting from nonlinearities in the surface gravity waves, and Ekman dynamics, resulting from viscosity and Coriolis forces related to the rotation of the earth. In the numerical hydrodynamic modeling of ocean currents, the effect of Stokes drift is often not considered and the knowledge about wind stress is inadequate, both of which would cause

Corresponding author address: Yadan Mao, School of Engineering, James Cook University, Townsville 4811 QLD, Australia. E-mail: yadan.mao@jcu.edu.au significant error in the results. Some work (Paduan and Shulman 2004) has been done to reduce numerical modeling error by using the HF radar data to improve the way wind forcing is introduced into the models. This has been achieved by assimilating the surface current data provided by HF radar into the modeling. HF radar is also used in the present study, but the emphasis in the present work is on investigating the relationship between surface currents and the wind under different conditions to provide more insight into the physical processes involved, which will benefit surface current prediction and improve accuracy in numerical modeling.

The response of surface currents to wind has two components: surface currents caused by momentum transfer through wind shear stress, and the Stokes mass transport. The former is explained by Ekman theory (Stewart 2005) and indicates a quadratic relation between the surface wind drift currents and the wind; the latter is caused by the nonlinear character of waves 
generated by wind (LeBlond and Mysak 1978) and indicates a linear relation between the Stokes drift and the wind. The momentum transfer from the wind into the ocean is through both wind shear stress and wave generation. Therefore, these two components are independent of each other, but work together to generate the current response. In different conditions, they play different roles.

As noted by Kirwan et al. (1979), resolving wind and wave drift components from each other and from a larger-scale main flow is a difficult experimental problem. Most laboratory and field investigations have focused on just one component.

Some exceptions include the analysis of Kirwan et al. (1979) and Wu (1983). The analysis of Kirwan et al. incorporated both of these two components. They found that linear theory was superior to the quadratic theory in explaining their data. However, because of some logistical compromises and uncertainty about the effect of wind drag on the exposed part of the buoy, they were unable to determine the role that Stokes drift played in the surface currents. In the study of $\mathrm{Wu}$ (1983), based on the wind-drag coefficient from laboratory experiments, and wave data compiled by Wiegel (1964), surface currents caused by wind stress and Stokes drift are calculated from empirical functions. However, both the wind and surface currents are treated as scalar and no angle relation was included in the analysis. In addition, the scarcity of the wave data used may have resulted in an inaccuracy of the wave parameters. The fetch-limited laboratory conditions inhibit the contribution of Stokes drift to the total currents.

Ekman's theory predicts that the angle between the wind-driven surface current vector and the wind vector is $45^{\circ}$. This is derived under the assumption of a constant vertical eddy viscosity for steady wind-driven currents in an infinitely homogenous ocean. This $45^{\circ}$ angle relation is generally considered to be on the high side in field observations (Madsen 1977). The shortcomings of a constant vertical eddy viscosity have long been recognized, and as a result the simple Ekman model has been extended to include variable eddy viscosity as well as boundary layers.

However, Stokes drift generated by waves also has an effect on the angle relation between the total surface drift currents and the wind. The study done by Lewis and Belcher (2003) demonstrates that the inclusion of the Stokes drift is the key to reconciling the discrepancies in the angular deflections of the steady-state currents. Polton et al. (2005) also found that the surface current direction is affected by the presence of ocean waves. These studies are based on adding the influence of Stokes drift into the Ekman model, and their analytical solution agrees well with the current profiles from previously published observational data and agrees better than the standard Ekman model.

Stokes drift is different under different sea states and this is reflected in the total response of the surface current to wind. Using data from HF ocean surface radar, this study aims to focus on the influence of fetch on the surface current response to wind and ascertain the role that Stokes drift and wind stress play in generating surface currents under different fetch conditions. HF radar data have the advantage over drifter data in studying the response of surface current to wind because the error introduced by the wind acting directly on buoys is excluded.

There has been some controversy about the ability of HF surface radar to measure Stokes drift. Theoretically, Creamer et al. (1989) described an approximation scheme that reproduces the effect of the lowest-order nonlinear behavior of surface waves, and captures important features of short waves interacting with longer waves. Their results indicate that the surface currents measured by the HF radar should respond to Stokes drift from all waves with wavelengths longer than the Bragg waves. Many recent research projects were conducted with the assumption that Stokes drift is present in the HF radar surface current data (Graber and Haus 1997; Gremes-Cordero et al. 2003; Chapron et al. 2005; Ullman et al. 2006). Ullman et al. (2006) used two ranges of the Coastal Ocean Dynamics Applications Radar (CODAR) measurements with different effective depths ( $\sim 0.5$ and $\sim 2.4 \mathrm{~m})$, and compared the radar data with the drifters at a depth of $0.65 \mathrm{~m}$. The comparison suggests the existence of Stokes drift in the HF radar data and the importance of effective depth of radar measurements.

We approached the above issues by identifying two typical fetch conditions with approximately the same wind speed, and comparing the difference in current response under these two conditions. The differences in current response to wind under these two typical fetch conditions suggest that not only is Stokes drift present in the HF radar measurement, but also that fetch plays a significant role in the response of surface current to wind by varying the magnitude of Stokes drift under different sea states.

\section{Experiment}

a. Site

The experiment was configured around a phasedarray $\mathrm{HF}$ radar system operating at $30 \mathrm{MHz}$. It is the Coastal Radar System (COSRAD), built as a research 
(a)

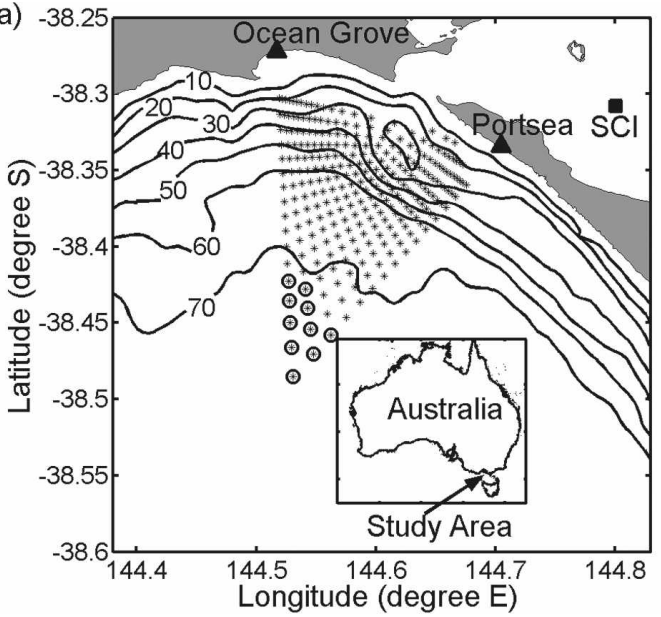

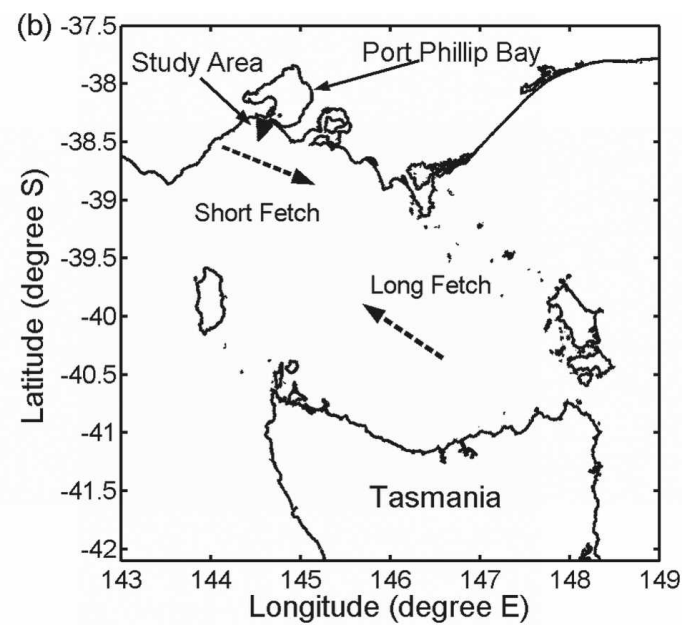

FIG. 1. Map of the study area (a) land (shaded), data grid points (asterisks), and bathymetry contours (m); two radar stations are marked as triangles, weather station SCI is marked as a square. The 10 grid points highlighted with circles are the ones chosen for the fetch study; (b) the study area in wider perspective shows how fetch varies with wind direction. The two dashed arrows represent the mean direction of wind during the short- and long-fetch duration in the analysis.

tool at James Cook University, and uses an eight-element antenna array for both transmit and receive modes. A pulse modulation is used and a transmit-receive switch is used to change from a high-energy transmit pulse to a low-noise receiver after each transmit pulse. The radar stations were set up at Portsea $\left(38^{\circ} 20^{\prime} 03.6^{\prime \prime} \mathrm{S}, 144^{\circ} 42^{\prime} 16.9^{\prime \prime} \mathrm{E}\right)$ and Ocean Grove (38 $\left.16^{\prime} 20.1^{\prime \prime} \mathrm{S}, 144^{\circ} 31^{\prime} 01.4^{\prime \prime} \mathrm{E}\right)$ in Bass Strait, near the entrance to Port Phillip Bay in Victoria, Australia. The area in which surface current maps are produced ranges from $38.3^{\circ}$ to $38.5^{\circ} \mathrm{S}$ latitude, and from $144.5^{\circ}$ to $144.7^{\circ} \mathrm{E}$ longitude, with the grid points shown as asterisks in Fig. 1a. The radar data archive consists of surface current vectors every hour at each of the 269 grid points within this area for a 1-month period, from 27 June 2001 to 26 July 2001.

The bathymetry in the near-coastal zone is shown in Fig. 1a. Five weather stations are located along the coast around the study area-two on the right side, two on the left side, and one inside the bay. Comparison among the wind records suggests that wind is quite uniform in the study area during the study period. Correlations of the wind data from each of these weather stations with the current data are all significant, with the highest correlation obtained from the weather station nearest to our study area, which is the one at the South Channel Island (marked as SCI in Fig. 1a). Therefore, wind data from an anemometer located 10 $\mathrm{m}$ above sea level on South Channel Island were used. Figure $1 \mathrm{~b}$ shows the study area in a wider perspective and the two typical fetch conditions under which current response to wind will be compared.

\section{b. Results}

The experiment was carried out by recording hourly values of surface currents for 30 days and mapping surface current vectors at the 269 grid points. Over the 30-day duration, only one hourly dataset was lost, because of environmental reasons.

The 10 grid points highlighted with circles at the south end of the mapped area had currents dominated by winds and all behaved in a similar way to wind changes. As will be mentioned later, these 10 grid points are selected for studying surface current response to wind under different fetch conditions. Figure 2 shows a typical time series of current at one of the grid points.

The high-frequency variation of the current is caused mainly by tides, while the low-frequency variation of the current is dominated by winds. Tidal analysis shows that $K_{1}$ and $M_{2}$ are the dominant tidal components. By filtering the surface current data with a 25-h boxcar filter, tide-generated currents are almost completely removed.

Hourly wind data were taken at South Channel Island for the 30-day period and the raw values are shown in Fig. 3.

\section{Surface current response to wind}

\section{a. Overall response over the whole time series}

Sea surface currents are generated by tides, winds, and other factors, such as geostrophic pressure gradients and density gradients. Currents are also influenced by bottom friction, land boundaries, and water flowing 

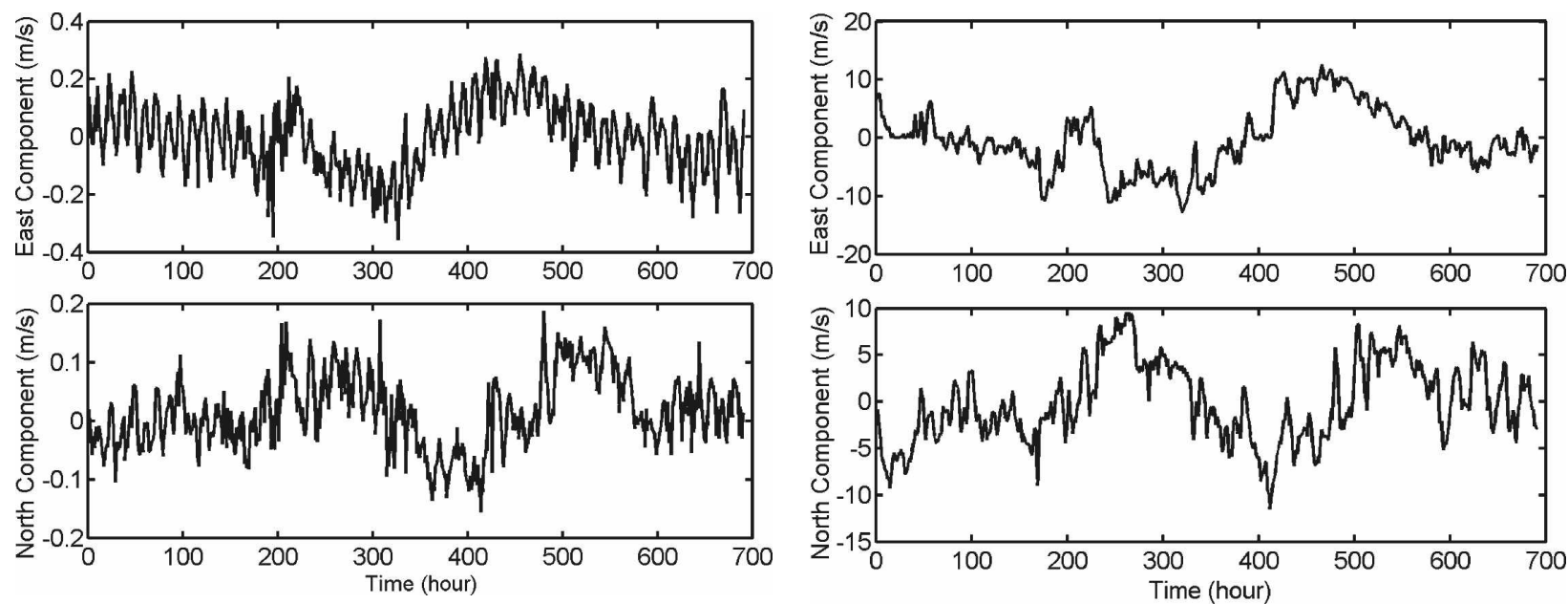

FIG. 2. Time series of HF radar current data at one of the southern grid points, reference time is 1700 Australian eastern standard time (UTC+10) 27 Jun 2001: (top) east and (bottom) north component.

into and out of rivers or bays. To evaluate the significance of wind in generating surface currents in our study area, a correlation analysis was conducted between the wind and filtered surface currents over the whole time series.

First both the wind data and the current data are filtered with 25-h boxcar low-pass filter. Let $\theta(t)$ be the angle between surface current vector $\mathbf{C}(t)$ and the wind vector $\mathbf{W}(t)$ at each time, and assume that the observed surface current is made up of a component $\mathbf{C}_{W}(t)$ responding to wind and a residual $\mathbf{C}_{R}(t)$. If $\phi$ is the angle between vector $\mathbf{C}_{W}(t)$ and the wind vector $\mathbf{W}(t)$, and $\phi$ is assumed to be constant over the whole time series, then the component of $\mathbf{C}(t)$ in the direction of $\mathbf{C}_{W}(t)$ at each time is $|\mathbf{C}(t)| \cos [\theta(t)-\phi]$. The assumption that $\phi$ is constant over the entire duration allows $\phi$ to vary with locations (e.g., for different bathymetry), but does not allow $\phi$ to change with wind speed or direction. Later on, when analyzing the influence of fetch on the response of surface current to wind, this condition on $\phi$ is relaxed.

The time series of $|\mathbf{C}(t)| \cos (\theta(t)-\phi)$ is correlated with the time series of wind speed $|\mathbf{W}(t)|$. By varying $\phi$ from $-180^{\circ}$ to $180^{\circ}$, the highest correlation between $|\mathbf{C}(t)| \cos [\theta(t)-\phi]$ and $|\mathbf{W}(t)|$ is found, and the corresponding $\phi$ is assumed to be the overall direction relation between $\mathbf{C}_{W}(t)$ and $\mathbf{W}(t)$ over the whole time series.

In performing the correlation analysis, a time shift was also considered. Figure 4 shows the correlation results for 1 of the 10 selected grid points. The correlation coefficient is plotted as a contour with a varying angle $\phi$ and time shifts.

FIG. 3. Wind data from an anemometer located on SCI, reference time is 1700 Australian eastern standard time (UTC+10) 27 Jun 2001: (top) east and (bottom) north component.

Results show that the highest correlation coefficient for currents at this grid point and the wind is found at zero time shift and at an angle of $\phi=20^{\circ}$. Figure 5a shows the correlation coefficient at zero time shift as angle $\phi$ varies, and Fig. $5 \mathrm{~b}$ shows the correlation coefficient versus time shift when $\phi$ is $20^{\circ}$. Comparing the results of several points on the current maps, it is found that the highest correlation coefficient almost always occurs at about zero time shift, but at different values of angle $\phi$. Therefore, we used zero time shift to find the value of $\phi$ at each grid point on the map. The values of $\phi$ and the corresponding maximum correlation coefficient are shown in Figs. 6a,b, respectively.

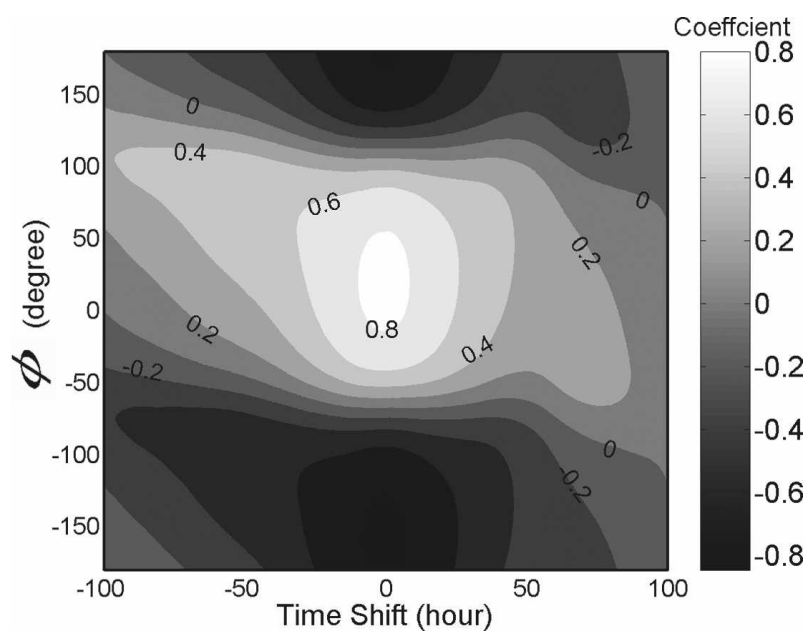

FIG. 4. Contours of correlation coefficient between $|\mathbf{C}(t)|$ $\cos (\theta(t)-\phi)$ and $|\mathbf{W}(t)|$ at one typical southern grid point vs $\phi$ and time shift. 

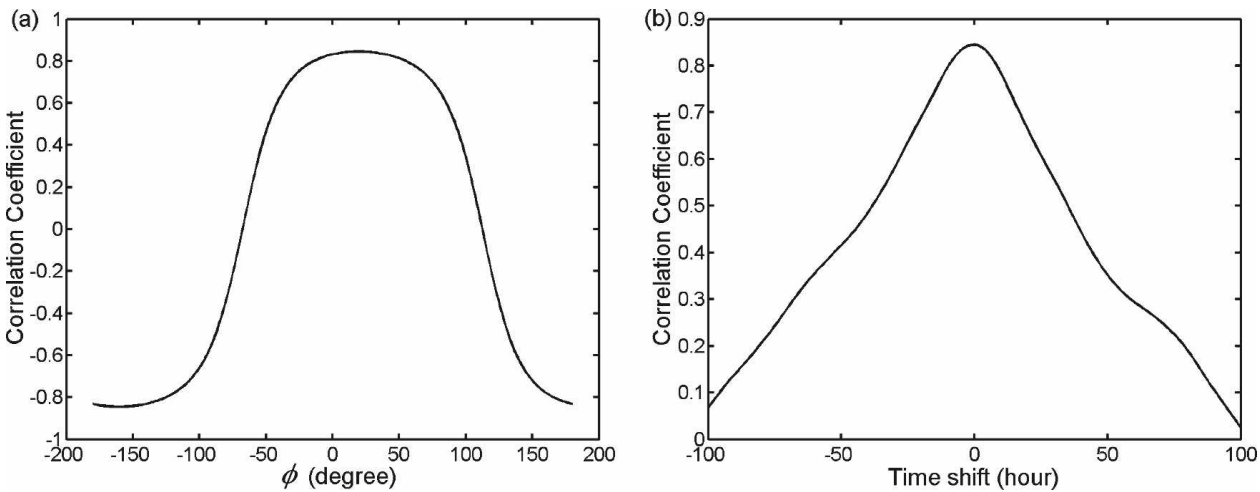

FIG. 5. Profile of the correlation coefficient corresponding to Fig. 4: (a) correlation coefficient at zero time shift with varying angle $\phi$ between current response and wind, and (b) correlation coefficient at $20^{\circ}$ with varying time shift.

Figure 6a is the contour of $\phi$ values optimized for maximum correlation. The angle is defined in a way that positive values indicate that the current is on the left side of the wind. Figure 6a suggests that for most areas, $\phi$ [i.e., the angle between current response $\mathbf{C}_{W}(t)$ and the wind $\mathbf{W}]$ is within the range of $10^{\circ}-45^{\circ}$, which is in agreement with other observational results (Huang 1979). The angle appears to decrease for grid points near to the coast, which can be explained by the larger effect of bottom friction there. For areas near the entrance of Port Phillip Bay, the value of $\phi$ varies widely and is often outside this range. Here, the surface currents appear to respond to flow into and out of the bay on the surface current map.

Figure $6 \mathrm{~b}$ shows the contour of correlation coefficient corresponding to the optimized $\phi$ values shown in Fig. 6a. It is shown that, except for areas near the entrance of Port Phillip Bay, the filtered current is highly correlated with wind for most of the study area, with a correlation coefficient around 0.8 . For the selected 10 grid points, after removing the effect of tide and wind, the residual current is found to be very small and behaves like noise (Mao et al. 2007). Therefore, it is considered that wind-generated currents dominate over other factors, such as geostrophic large-scale currents, for this part of the study area during this period of time.

Figures $6 \mathrm{a}, \mathrm{b}$ reveal the overall response of surface current to wind considering the whole time series; the linear correlation conducted over the whole time series is mainly aimed at finding the significance of wind in generating surface currents. The high correlation suggests that the wind is the dominant force in generating the filtered surface current for the grid points at the southern end of the current map.

Therefore, when we later investigate the influence of fetch on the response of surface current to wind in the southern end of the current map, the filtered surface current is considered to be generated by wind only. We
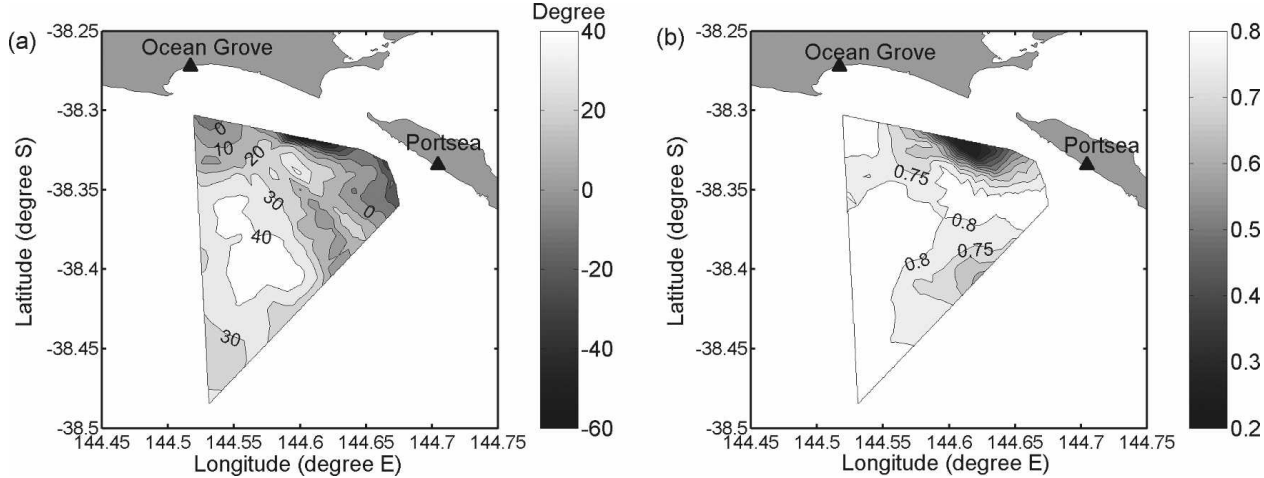

FIG. 6. Contours related to the response of surface current to wind over the whole time series; (a) the $\phi$ value is optimized for maximum correlation. Positive angle indicates that the responding current is on the left of the wind. (b) The correlation coefficient between the surface current and wind corresponding to the optimized direction relation in (a) is given. 

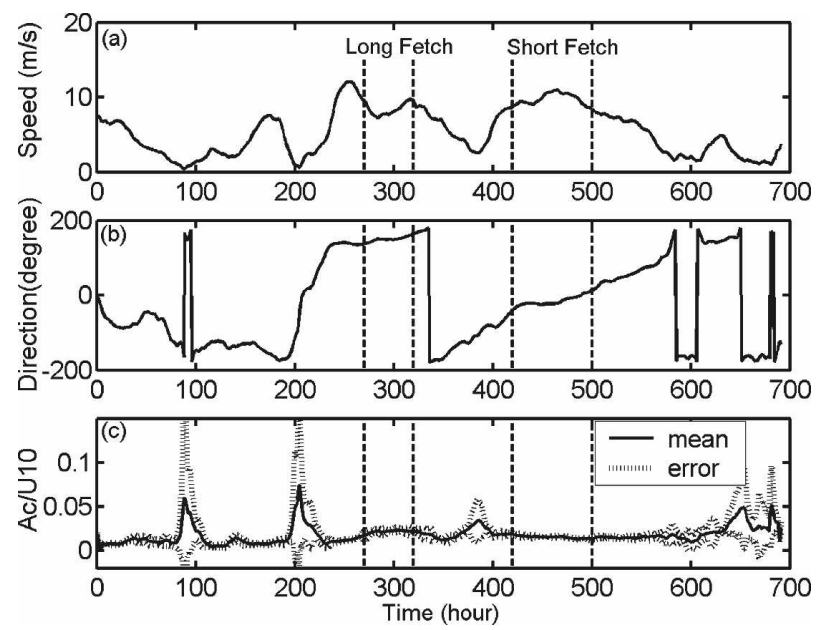

FIG. 7. The selected long- and short-fetch periods from (a) time series of the filtered wind speed, (b) time series of the angle of the filtered wind vector measured anticlockwise from east, and (c) time series of the average ratio of current speed to wind speed (solid line) with error bar (dashed line). The reference time is 1700 Australian eastern standard time (UTC + 10) 27 Jun 2001.

are interested in how fetch influences the response of surface current to wind. To this end, we need to identify periods that represent a variety of fetch conditions with reasonably stable wind.

\section{b. Response under long- and short-fetch periods}

After being filtered with a 25-h boxcar low-pass filter, the wind time series is shown in Figs. 7a,b in terms of speed and direction, respectively. The angle is defined trigonometrically, anticlockwise from east, and it shows the vector wind direction.

Given Figs. 7a,b and the geography map of Fig. 1b, we identified the period $(230-320 \mathrm{~h})$ when the wind was relatively constant in speed and direction over a long fetch, in addition to another period (420-500 h) over a short fetch. As will be mentioned later, the wave growth during the first $36 \mathrm{~h}$ of the long-fetch period is duration limited. Because we are mainly concerned about the influence of fetch, the interval of $270-320 \mathrm{~h}$ in the time series is chosen to represent the long-fetch periods. The short- and long-fetch periods are marked with dashed lines in Fig. 7. For the long-fetch section, the fetch is around $380 \mathrm{~km}$; the mean speed of wind is $8.4 \mathrm{~m} \mathrm{~s}^{-1}$, with a standard deviation of $0.8 \mathrm{~m} \mathrm{~s}^{-1}$; and the mean direction of the wind vector is $149.9^{\circ}$, anticlockwise from the east, with a standard deviation of $6.3^{\circ}$. For the short-fetch section, the fetch is around 30 $\mathrm{km}$; the mean wind speed is $9.8 \mathrm{~m} \mathrm{~s}^{-1}$, with a standard deviation of $0.7 \mathrm{~m} \mathrm{~s}^{-1}$; and the mean direction of the wind is $-15.8^{\circ}$, anticlockwise from the east, with a standard deviation of $12.4^{\circ}$.

The average ratio of surface current speed $A_{C}$ to wind speed $U_{10}$ measured at $10 \mathrm{~m}$ above sea level is shown in Fig. 7c with error bars marked as dotted lines. The errors of the current speed are calculated by the standard deviation over the 10 grid points divided by the square root of the number of grid points; the errors of the wind speed are calculated by the standard deviation over the adjacent 10 -h period divided by the square root of the number of hours. Comparing Fig. 7a with Fig. 7c, it can be seen that large error bars generally correspond to low wind speeds. Ratio values that are unreasonably large also have large error bars and therefore can be ignored. For the selected long- and shortfetch periods, the error bar is small, and hence the ratio values are significant. The average ratio $A_{C} / U_{10}$ is 0.021 for the long-fetch period and 0.015 for the short-fetch period.

Typical maps of surface currents under the long- and short-fetch conditions are shown in Figs. 8a,b, respectively. The currents at the southern end of the mapped area behave uniformly and appear to respond mainly to the wind. At the northern end of the map, the currents are complex and appear to respond to the flow into and out of Port Phillip Bay. For the middle area, the currents follow the bathymetry lines. This is reasonable, because the bathymetry gradients around the $60-\mathrm{m}$ bathymetry line are large and variable; areas with bottoms shallower than $60 \mathrm{~m}$ have larger bathymetry gradients. As depth increases, the gradients become smaller. Therefore, for areas near the coast with bathymetry shallower than $60 \mathrm{~m}$, the currents are steered along the bathymetry contours.

The criteria we adopt here in choosing the grid points to study the influence of fetch on surface currents are as follows: 1) a high correlation with the wind (with correlation coefficient $>0.8$ ), 2) reasonably deep water and distant from the coast, and 3) far from the area with large bathymetry gradients. Therefore, only 10 points, as highlighted in Fig. 1, are chosen to study current response to wind under the short- and the long-fetch conditions. As shown in Fig. 6b, for these 10 grid points, the surface current is highly correlated with the wind, with the correlation coefficient higher than 0.8 .

Comparing Figs. 8a,b for the selected 10 grid points, it is noticeable that the angle between the surface current and the wind is smaller in the long- than in the short-fetch condition. Because the current map shows the current only at a particular time, the difference in direction relation might not be representative of other times. Therefore, the direction relation averaged over the 10 selected grid points is shown in Fig. 9 as time series over the long- and the short-fetch periods. The errors of current direction and wind direction are calculated in the same way as for current speed and wind 

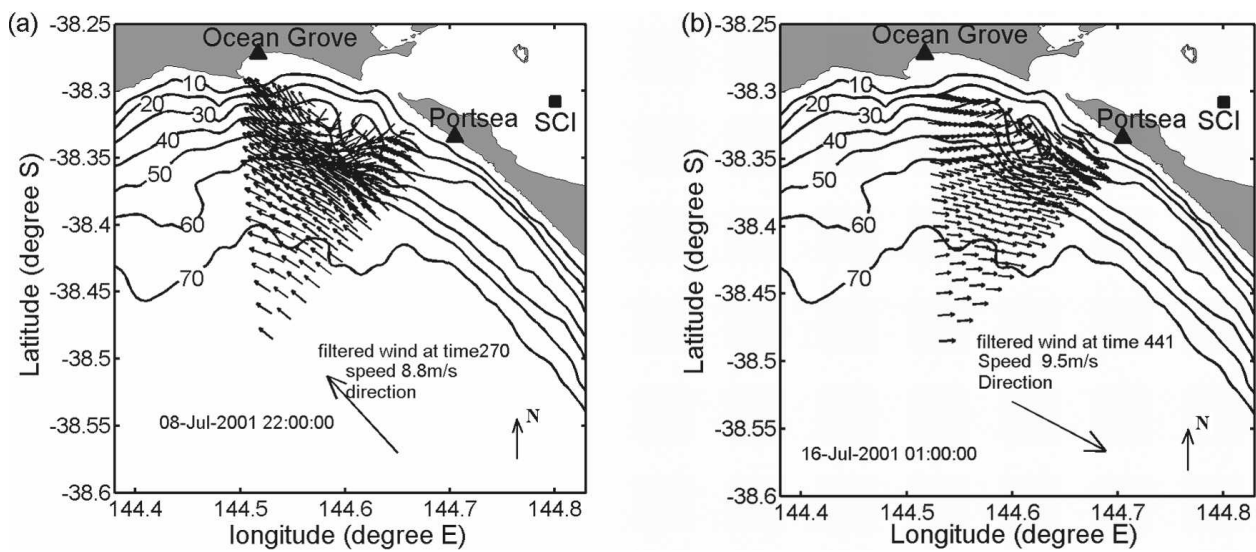

FIG. 8. Typical map of filtered surface currents under (a) long- and (b) short-fetch conditions.

speed in Fig. 7. The condition on $\phi$ is now relaxed; $\phi$ is the angle between surface currents and wind averaged over the 10 selected grid points and is assumed to vary with fetch conditions: it is not constant as before over the entire 30-day duration.

As shown in Fig. 9, for the long-fetch period, the angle $\phi$ between surface currents and wind ranges from $6.8^{\circ}$ to $19.9^{\circ}$, with an average of $14.4^{\circ}$ and standard deviation of $3.8^{\circ}$. For the short-fetch period, the angle ranges from $17.8^{\circ}$ to $36.2^{\circ}$, with an average of $24.4^{\circ}$ and standard deviation of $4.9^{\circ}$. On average, the angle $\phi$ between surface currents and wind is $10^{\circ}$ larger in the short- than in the long-fetch conditions.

Because the grid points remain the same under the
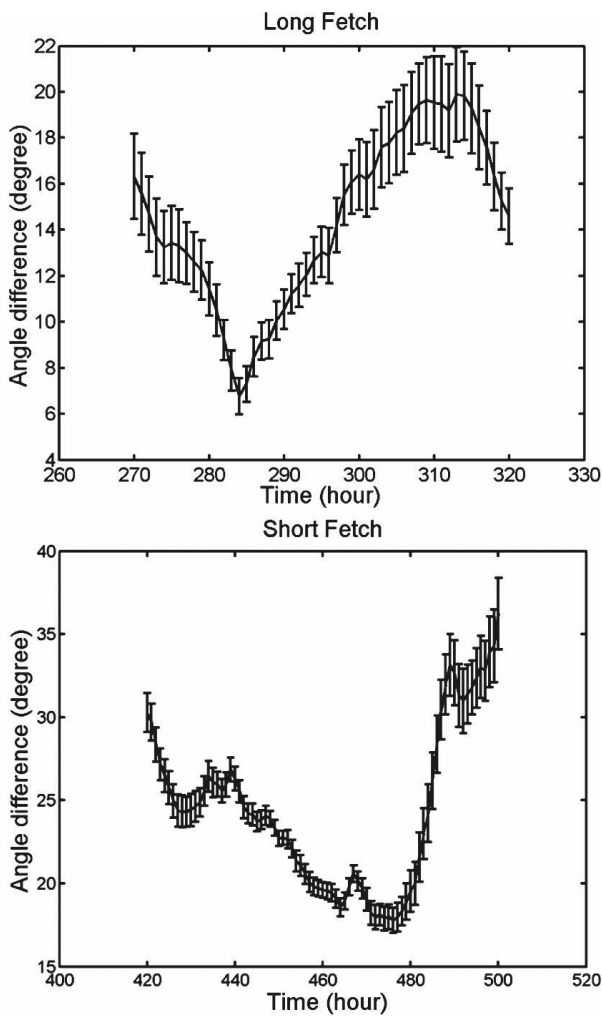

FIG. 9. (left) Direction of the wind vector and surface current vector over the (top) long- and (bottom) short-fetch periods; the angle is measured anticlockwise from the east. (right) Direction difference of surface current and wind over the long- and short-fetch periods; positive angle means the current vector is on the left side of the wind vector. 
long- and the short-fetch conditions, factors such as geography, bottom friction, and vertical eddy viscosity that may influence the value of $\phi$ are assumed to remain the same in the long- and short-fetch conditions. Therefore, the difference in the value of $\phi$ under these two conditions can be attributed to the difference in wind fetch conditions.

In summary, the above results suggest that the ratio of the surface current speed to wind speed $A_{C} / U_{10}$ is larger under long- than short-fetch conditions. Also, the angle $\phi$ between the surface current and the wind is smaller under long- than short-fetch conditions.

To explain these differences, we need to understand that wind generates surface currents as a result of momentum transfer through both wind stress acting directly on the ocean surface and Stokes drift induced by the nonlinearity of waves. As the wave spectrum develops with fetch, the magnitude of Stokes drift also varies with fetch.

\section{Surface current components}

The response of surface current to wind is composed of both Ekman-type currents generated by wind stress and the Stokes drift. The former is governed by Ekman theory and the latter is governed by Stokes mass transport theory.

\section{a. Ekman-type currents}

Assuming a steady, homogeneous, horizontal flow with friction on a rotating earth and constant vertical eddy viscosity, the speed of surface current is derived from the momentum equation as (Stewart 2005)

$$
V_{E}=\frac{T}{\sqrt{\rho_{w}^{2} f A_{z}}},
$$

where $T$ is the wind stress, $\rho_{w}$ is the water density, $f=$ $2 \omega \sin \varphi$ is the Coriolis parameter, $\omega$ is the rotation rate of the earth, $\omega=7.292 \times 10^{-5}\left(\mathrm{rad} \mathrm{s}^{-1}\right)$, and $A_{z}$ is the eddy viscosity. A value for $A_{z}$ cannot be obtained from theory. Instead, it must be calculated from data collected in wind tunnels or measured in the surface boundary layer at sea.

According to Ekman theory, surface wind drift currents are $45^{\circ}$ to the left of the wind in the Southern Hemisphere.

Wind stress $T$ can be calculated from

$$
T=\rho_{a} C_{D} U_{10}^{2},
$$

where $C_{D}$ is the drag coefficient, $\rho_{a}$ is the air density. Substituting (2) into (1), we obtain

$$
V_{E}=\frac{\rho_{a} C_{D} U_{10}^{2}}{\sqrt{\rho_{w}^{2} f A_{z}}} .
$$

Many studies have been done to obtain the drag coefficient $C_{D}$. A form given by $\mathrm{Wu}(1980)$ is

$$
C_{D}=\left(0.8+0.065 U_{10}\right) \times 10^{-3} U_{10}>1 \mathrm{~m} \mathrm{~s}^{-1} .
$$

Garratt (1992) gives

$$
C_{D}=\left(0.75+0.067 U_{10}\right) \times 10^{-3} .
$$

More recently, Yelland and Taylor (1996) give

$$
\begin{aligned}
& C_{D}=\left(0.29+\frac{3.1}{U_{10}}+\frac{7.7}{U_{10}^{2}}\right) \times 10^{-3} 3 \leq U_{10} \leq 6 \mathrm{~m} \mathrm{~s}^{-1} \\
& C_{D}=\left(0.60+0.07 \times U_{10}\right) \times 10^{-3} 6 \leq U_{10} \leq 26 \mathrm{~m} \mathrm{~s}^{-1} .
\end{aligned}
$$

These findings suggest that at relatively high wind speed, the drag coefficient increases with the wind speed. Using (5), we calculate the ratio of standard deviation of $C_{D}$ versus the mean of $C_{D}$ for the long- and short-fetch periods. The ratio is $4.1 \%$ for the long-fetch period and $3.6 \%$ for the short-fetch period. Therefore, $C_{D}$ is regarded as relatively constant over the selected fetch periods, and thus (3) suggests that a quadratic relation between $V_{E}$ and $U_{10}$ is a good approximation for the relation between the wind-generated current speed and the wind speed.

\section{b. Stokes drift}

\section{1) EXPRESSION OF STOKES DRIFT}

The Stokes drift can be expressed as (Bye 1967)

$$
V_{S}=\omega a^{2} k e^{-2 k z},
$$

where $\omega, a$, and $k$ are the radian frequency, amplitude, and wavenumber, respectively, for the waves, and $z$ is the depth measured from the surface downward. In our experiment, the $\mathrm{HF}$ radar $(30 \mathrm{MHz})$ measures the average current velocity from the surface to a depth of the order of $0.4 \mathrm{~m}$ (Stewart and Joy 1974), which is well within the depth $1 /(2 k)$ over which Stokes drift is usually defined to be effective [the wavenumber $k$ of dominant waves can be derived from functions of wave parameters that are presented later, for the short-fetch condition $1 /(2 k) \sim 1.5 \mathrm{~m}$ and for the long-fetch condition $1 /(2 k) \sim 4.5 \mathrm{~m}]$; hence, it is expected that Stokes drift is present in the data. This experiment is similar to one of the cases presented by Ullman et al. (2006) for the standard-range CODAR $(25 \mathrm{MHz}$, effective depth $\sim 0.5 \mathrm{~m}$ ) where Stokes drift is accounted for in the analysis. The exponential term in (7) is close to 1 , 
under both the short- and long-fetch conditions, and therefore

$$
V_{S} \approx \omega a^{2} k .
$$

Because contributions to the Stokes drift current come mainly from wave components at the spectral peak, the surface mass transport calculated from the average characteristic of dominant waves provides a reliable approximation to that calculated from the wave spectrum (Wu 1983). Therefore, we consider only the wave component at the spectral peak when calculating the Stokes drift.

If $m_{0}$ is the variance or total energy of the wave record, $\omega_{p}$ is the peak frequency of the spectrum, and $X$ is the fetch for the wave field, the corresponding nondimensional terms $m_{0}^{\prime}, \omega_{p}^{\prime}$, and $X^{\prime}$ can be expressed as

$$
m_{0}^{\prime}=\frac{g^{2} m_{0}}{U_{10}^{4}}, \quad \omega_{p}^{\prime}=\frac{U_{10} \omega_{p}}{g}, \quad X^{\prime}=\frac{g X}{U_{10}^{2}},
$$

where $g$ is gravity acceleration. Thus, the nondimensional fetch for our long-fetch period is about 54000 , and for the short-fetch period is about 3100 .

The significant wave height $H_{s}$ is defined as (Janssen 2004)

$$
H_{s}=4 \sqrt{m_{0}} .
$$

Hence, for significant wave amplitude $a$, we have

$$
a=\frac{1}{2} H_{s}=2 \sqrt{m_{0}} ;
$$

and, from wave dispersion theory, we have

$$
k=\frac{\omega^{2}}{g} .
$$

Substituting (9), (11), (12) into (8) yields the magnitude of Stokes drift with respect to the nondimensional wave parameters

$$
V_{S}=4 \omega_{p}^{\prime 3} m_{0}^{\prime} U_{10} .
$$

Equation (13) suggests that at a certain wave development state, there is a linear relation between the surface Stokes drift and the wind speed.

\section{2) INFLUENCE OF FETCH ON WAVE PARAMETERS}

To calculate Stokes drift, wave parameters need to be known. Much work has been done to establish the empirical functions of wave parameters versus nondimensional fetch (Dobson et al. 1989; Donelan et al. 1985; Hasselmann et al. 1973; Kahma 1981; Kahma and Calkoen 1992). All of these expressions are obtained under different circumstances: some are obtained from lakes, others are from the ocean; some are of stable stratification, and others are of unstable conditions.

For short fetches, when the wave is in fast growth, many different fetch-limited formulas for wave parameters have been suggested. Excluding formulas derived from unstable conditions, we have the following list:

Joint North Sea Wave Project (JONSWAP) fetchlimited wave evolution (Hasselmann et al. 1973),

$$
\begin{aligned}
& m_{0}^{\prime}=1.6 \times 10^{-7} X^{\prime}, \\
& \omega_{p}^{\prime}=21.98 X^{\prime-0.33} ;
\end{aligned}
$$

Lake Ontario (Donelan et al. 1985),

$$
\begin{aligned}
& m_{0}^{\prime}=8.415 \times 10^{-7} X^{\prime 0.76}, \\
& \omega_{p}^{\prime}=11.6 X^{\prime-0.23} ;
\end{aligned}
$$

North Atlantic open ocean (Dobson et al. 1989),

$$
\begin{aligned}
m_{0}^{\prime} & =1.27 \times 10^{-6} X^{\prime 0.75}, \\
\omega_{p}^{\prime} & =10.68 X^{\prime-0.24} ;
\end{aligned}
$$

an average expression with error bars (Young 1999), ${ }^{1}$

$$
\begin{aligned}
& m_{0}^{\prime}=\min \left\{\begin{array}{c}
(7.5 \pm 2.0) \times 10^{-7} X^{\prime 0.8} \\
(3.6 \pm 0.9) \times 10^{-3}
\end{array}\right. \\
& \omega_{p}^{\prime}=\max \left\{\begin{array}{l}
(12.56 \pm 1.88) X^{\prime-0.25} \\
0.82 \pm 0.13
\end{array}\right.
\end{aligned}
$$

The above fetch-limited Eqs. (14)-(16) apply only to short-fetch condition when the wave is in fast growth. Despite their differences, there is a common form that nondimensional wave energy and frequency are power functions of nondimensional fetch; it is only the coefficient and the exponent that vary between the different models. All of the above expressions of wave parameters are in agreement, with the expectation that as nondimensional fetch increases, wave energy increases and the peak frequency decreases.

Once the fetch and duration are long enough that the sea reaches a fully developed state for a given constant wind speed, waves will not continue to grow even when either the fetch or duration increase further. The nondimensional parameters of this constant state are given as (Pierson and Moskowitz 1964)

$$
m_{0}^{\prime}=3.64 \times 10^{-3}, \quad \omega_{p}^{\prime}=0.82 .
$$

Between the short fetch with a stable wave growth rate and the long fetch, where waves cease to grow, there is a transition region where the growth rate gradually slows down. For this transition region, the above-mentioned fetch-limited wave growth formulas

\footnotetext{
${ }^{1}$ Both minimum and maximum are amended.
} 

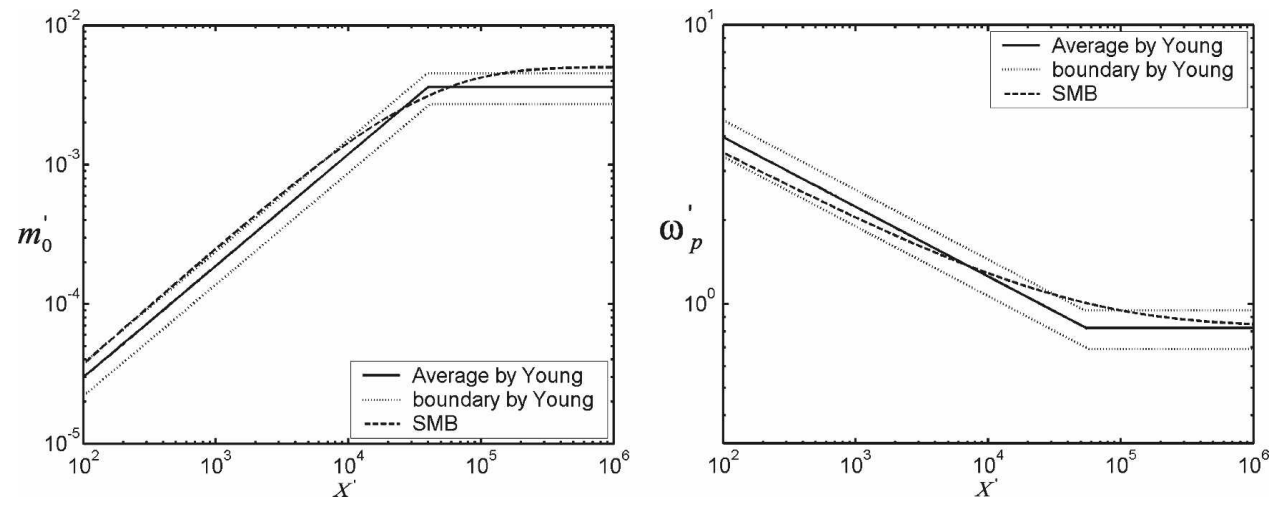

FIG. 10. (left) Nondimensional total energy $m_{0}^{\prime}$ of wave record and (right) nondimensional frequency $\omega_{p}^{\prime}$ at the spectral peak vs nondimensional fetch $X^{\prime}$.

do not apply, because these empirical formulas are derived from fitting to the data only in the short-fetch region.

Therefore, for the transition regime, we look for empirical functions that are derived by fitting to data for both short and long fetches. During World War II, Sverdrup and Munk (1944, 1946) compiled existing data from a number of sources, including the field and laboratory. Bretschneider (1952a,b) later augmented and refined the results. The results have been summarized in CERC (1973), and the growth curve became know as the Sverdrup-Munk-Bretschneider (SMB) curve:

$$
\begin{aligned}
& m_{0}^{\prime}=5.0 \times 10^{-3} \tanh ^{2}\left(0.0125 X^{\prime 0.42}\right) \\
& \omega_{p}^{\prime}=\frac{0.833}{\tanh \left(0.077 X^{\prime 0.25}\right)} .
\end{aligned}
$$

Nondimensional variance of wave energy and nondimensional peak frequency in (17) and (19) are plotted in Fig. 10. It can be seen that the transition region is from about $10^{4}$ to about $10^{5}$ in nondimensional fetch. Hence, the long-fetch condition in our study with a nondimensional fetch of 54000 belongs to the transition region in the fetch-limited wave growth regime. Therefore, for calculating the wave parameter in this region, it is better to use (19), which includes the transition region, because it is derived from fitting to both long and short nondimensional fetches. The short-fetch condition with a nondimensional fetch of 3100 belongs to the short-fetch regime where the wave spectrum is in fast development. Wave parameters in this regime can be calculated using (14)-(17).

Because wave development is limited both by fetch and duration, the duration for wave development also needs to be considered. Because we are mainly concerned about the influence of fetch on the response of the surface current to wind, we need to know when the wave is not duration limited. An empirical function was derived by CERC (1973) to calculate the duration for wave development,

$$
\varsigma=K \exp \left\{\left[A\left(\ln X^{\prime}\right)^{2}-B \ln X^{\prime}+C\right]^{1 / 2}+D \ln X^{\prime}\right\}
$$

where $K=6.5882, A=0.0161, B=0.3692, C=2.2024$, and $D=0.8798$. Here, $\mathrm{s}$ is the nondimensional duration needed for wave development as a function of nondimensional fetch $X^{\prime}$. As shown in Fig. 11, the duration required for wave development increases with increasing nondimensional fetch. The duration needed for wave development for the long- and short-fetch periods is marked in Fig. 11 as dashed lines.

For the short-fetch section, the wave growth will be duration limited for the first $3.6 \mathrm{~h}$; for the long-fetch section, the wave growth will be duration limited for the first $36.1 \mathrm{~h}$. Hence, for long fetches, the influence of duration on wave growth cannot be ignored. Because the long-fetch wind starts around $230 \mathrm{~h}$ in the time series, we choose $270-320 \mathrm{~h}$ to be the section for our long-fetch case, in order to exclude the effect of duration on wave development.

\section{Current data analysis}

\section{a. Determination of coefficients for Ekman-type surface currents and Stokes drift}

As discussed above, the filtered surface current is mainly driven by the local wind, and the surface current is predominantly a combination of wind stress induced current vector $\mathbf{V}_{E}$ and Stokes drift vector $\mathbf{V}_{S}$. We express the surface current in the following way:

$$
\mathbf{V}=\mathbf{V}_{E}+\mathbf{V}_{S}
$$




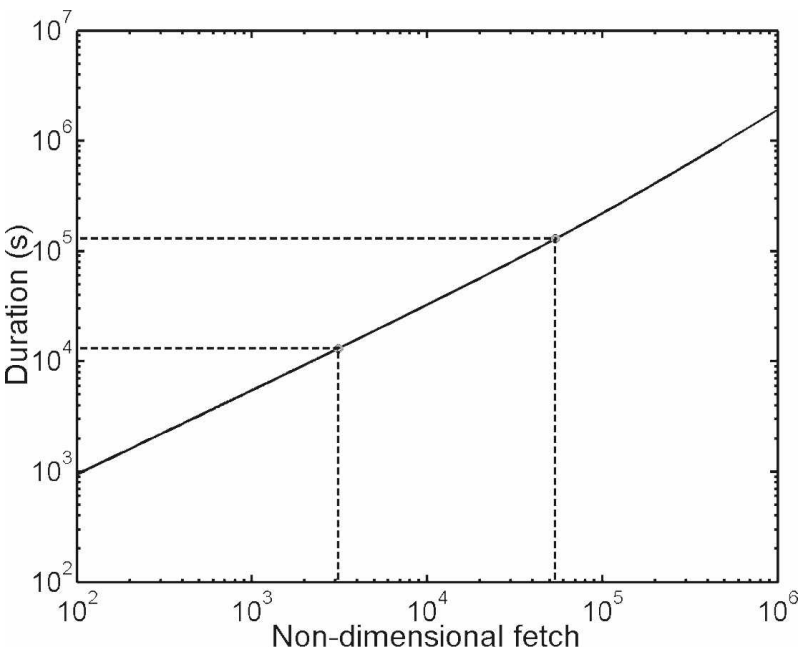

FIG. 11. Duration required for the full wave development vs nondimensional fetch (CERC 1973); the dashed lines show the two durations for the long- and short-fetch conditions studied.

With the quadratic and linear theories and the angle relations between the surface current and the wind explained above, we have

$$
\begin{aligned}
& \mathbf{V}_{E}=c_{1} U_{10}^{2}\left[\cos \left(\alpha+\frac{\pi}{4}\right)+\mathbf{i} \sin \left(\alpha+\frac{\pi}{4}\right)\right], \\
& \mathbf{V}_{S}=c_{2} U_{10}(\cos \alpha+\mathbf{i} \sin \alpha),
\end{aligned}
$$

where $U_{10}$ is the wind speed, $\alpha$ is the angle of wind anticlockwise to the east, and $c_{1}$ and $c_{2}$ are related with drag coefficient and wave parameters, respectively. The real and imaginary parts represent components in the east and north directions, respectively. Substituting (22) into (21) yields the surface current equation,

$$
\begin{aligned}
& u=a_{1} U_{10}^{2}(\cos \alpha-\sin \alpha)+a_{2} U_{10} \cos \alpha \\
& v=a_{1} U_{10}^{2}(\cos \alpha+\sin \alpha)+a_{2} U_{10} \sin \alpha,
\end{aligned}
$$

where $u$ and $v$ are the observed east and north components of surface current, respectively. Here, $a_{1}$ and $a_{2}$ are the two coefficients corresponding to $c_{1}$ and $c_{2}$ in (22); $a_{1}=\sqrt{2} / 2 c_{1}$ and $a_{2}=c_{2}$. The first term on the right side of (23) represents the component of the wind stress-generated surface current, including the quadratic relation and the $45^{\circ}$ angle relation. The last term of (23) signifies the component of Stokes mass transport that is in the same direction as the wind, including the linear relation. Because the Stokes drift is in the wave direction, our assumption that the Stokes drift is in the wind direction implies that the wave is in the same direction as the wind. It is common practice to assume that the wave propagation direction agrees with the wind direction. Donelan et al. (1985) pointed out
TABLE 1. Coefficient for Ekman-type current $\left(a_{1}\right)$ and Stokes drift $\left(a_{2}\right)$ and average fit error $(\mathrm{dc})$ for the 10 grid points

\begin{tabular}{lccccccc}
\hline \hline \multirow{2}{*}{$\begin{array}{c}\text { Grid point } \\
\text { No.* }\end{array}$} & \multicolumn{3}{c}{ Long-fetch period } & & \multicolumn{3}{c}{ Short-fetch period } \\
\cline { 2 - 3 } \cline { 6 - 8 } & $a_{1}$ & $a_{2}$ & $\mathrm{dc}$ & & $a_{1}$ & $a_{2}$ & $\mathrm{dc}$ \\
\hline 253 & 0.0005 & 0.0132 & 0.0143 & & 0.0006 & 0.0083 & 0.0192 \\
254 & 0.0007 & 0.0141 & 0.0171 & & 0.0006 & 0.0077 & 0.0235 \\
255 & 0.0007 & 0.0161 & 0.0173 & & 0.0006 & 0.0084 & 0.0225 \\
256 & 0.0006 & 0.0165 & 0.0167 & & 0.0006 & 0.0083 & 0.0192 \\
257 & 0.0005 & 0.0171 & 0.0246 & & 0.0006 & 0.0076 & 0.0196 \\
236 & 0.0006 & 0.0147 & 0.0211 & & 0.0006 & 0.0073 & 0.0229 \\
237 & 0.0007 & 0.0149 & 0.0297 & & 0.0006 & 0.0077 & 0.0205 \\
238 & 0.0008 & 0.0148 & 0.0250 & & 0.0006 & 0.0081 & 0.0179 \\
239 & 0.0006 & 0.0152 & 0.0231 & & 0.0006 & 0.0082 & 0.0175 \\
219 & 0.0007 & 0.0132 & 0.0294 & & 0.0006 & 0.0089 & 0.0221 \\
Average & 0.000625 & 0.0150 & 0.0218 & & 0.0006 & 0.0080 & 0.0205 \\
\hline
\end{tabular}

* The position of the 10 grid points on the current map corresponding to the order in this table is from the bottom to the top and from the left to the right.

that when the wind is not perpendicular to the land boundary, the gradient in the fetch about the wind direction is large and the wave direction will not agree with the wind and will be biased toward the longer fetch. In our dataset, no wave information is available; otherwise, the dominant wave direction would be derived from the wave data. However, the shape of Lake Ontario, where Donelan et al. (1985) made their observations, is quite elongated and enclosed. For our study area, the water body is within a fairly open geometry, and in the short-fetch duration the wind direction is rather perpendicular to the shoreline in the early half of the duration and is favorable for obtaining long fetch; hence, the effect of the water body geometry on the wave direction is expected to be small. Therefore, in applying Eq. (23), the problem is simplified by assuming that the direction of dominant wave agrees with the wind direction.

To ascertain the role $\mathbf{V}_{E}$ and $\mathbf{V}_{S}$ each play under different conditions, the least squares fitting process is applied to (23) to minimize the mean square speed residual. The least squares fitting process was conducted on each of the 10 chosen points separately, with a set of $a_{1}$ and $a_{2}$ values obtained for each grid point (Table 1). The result of the fitting for 1 of the 10 grid points is shown in Fig. 12. The real current data and the model result derived from the value of $a_{1}$ and $a_{2}$ at that point are shown for the short- and long-fetch periods. Figure 12 also shows the current produced separately by wind stress and Stokes mass transport. It can be clearly seen that under the long-fetch condition, Stokes drift is dominant in generating the surface current, while under the short-fetch condition, Stokes drift is equally important as wind stress in generating the surface current. 

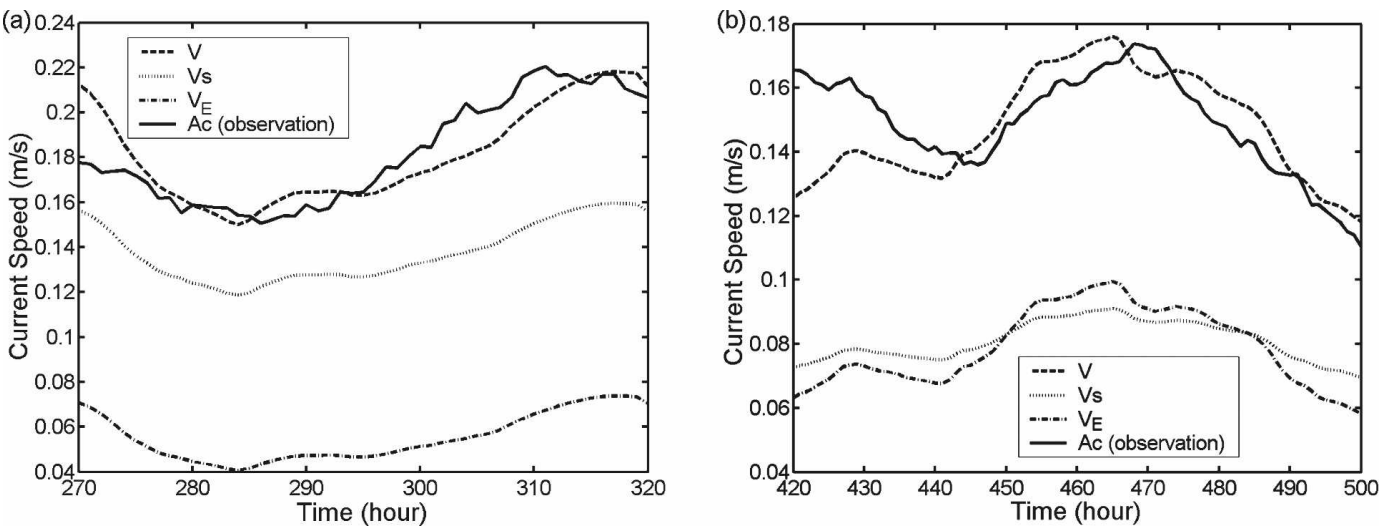

FIG. 12. Model results at grid point 255 for (a) long- and (b) short-fetch periods; the total surface current speed $V$ (dashed), the observed surface current speed $A_{C}$ (solid), speed of the Ekman-type current $V_{E}$ (dash dotted), and Stokes drift $V_{S}$ (dotted).

Table 1 shows the least squares fitting results of coefficients $a_{1}$ and $a_{2}$ for the 10 grid points during the long- and short-fetch periods, as well as the average fitting error dc between the observed current and the model results. The modeling process here is done for each grid point in order to evaluate the generality of the value of coefficient $a_{1}$ and $a_{2}$ so as to verify the influence of fetch on the values. The average coefficient value of these different points can be used for current prediction under the corresponding environmental condition.

Results show that the value of the coefficient $a_{2}$ for Stokes drift is much smaller under the short- than longfetch conditions. This suggests that under long-fetch conditions, resulting from more mature wave development, the influence of Stokes drift is much stronger than under short-fetch conditions. In contrast, the similarity of the value of the coefficient $a_{1}$ under these two fetch conditions suggests that fetch condition does not have much influence on the wind stress-generated surface current $\mathbf{V}_{E}$. As indicated by Eq. (3), the value of $\sqrt{2} a_{1}$ represents the magnitude of $\rho_{a} C_{D}\left(\rho_{w}^{2} f A_{z}\right)^{-1 / 2}$; therefore, the similarity of $a_{1}$ under the two fetch conditions suggests that the value of $C_{D} A_{z}^{-1 / 2}$ was not affected much by the sea state because other parameters, such as water density $\rho_{w}$, air density $\rho_{a}$, and Coriolis parameter $f$, were independent of fetch and assumed to be the same under different fetch conditions. The dependence of drag coefficient $C_{D}$ on sea state has been a contentious issue; recently, some studies show that there is lack of evidence of this dependence (Janssen 1997; Yelland et al. 1998). In our study, a conclusion on whether the drag coefficient $C_{D}$ depends on sea state might be too early without further information of the variation of eddy viscosity $A_{z}$ with fetch. However, results suggest that wind stress-generated surface current does not have much dependence on the fetch condition, and as a result of wave development with fetch, Stokes drift increases with fetch, contributing to a larger ratio of total current speed to wind speed $A_{C} / U_{10}$.

\section{b. Comparison with results derived from empirical wave growth functions}

Finally, we are going to compare the values of the Stokes drift coefficients $a_{2}$ derived from our data analysis with those calculated from previously mentioned empirical equations. For short nondimensional fetches $\left(<10^{4}\right)$, which apply to our short-fetch condition, (14)(17) and (19) can be used to calculate the wave parameters. Substituting them into (13), the following equations expressing Stokes drift as function of nondimensional fetch $X^{\prime}$ and wind speed $U_{10}$ are obtained:

$$
\begin{aligned}
& V_{S}=0.0068 \times X^{\prime 0.01} \times U_{10}, \\
& V_{S}=0.0053 \times X^{\prime 0.07} \times U_{10}, \\
& V_{S}=0.0062 \times X^{\prime 0.03} \times U_{10}, \\
& V_{S}=0.0059 \times X^{\prime 0.05} \times U_{10}, \\
& V_{S}=1.164 \times 10^{-2} \times \frac{\tanh ^{2}\left(0.0125 X^{\prime 0.42}\right)}{\tanh ^{3}\left(0.077 X^{\prime 0.25}\right)} \times U_{10} .
\end{aligned}
$$

For the transition zone (which applies to the longfetch condition), only (19) applies for the wave parameters, thus Stokes drift can be calculated from (28). Figure 13 shows the ratio $V_{S} / U_{10}$ derived from empirical Eqs. (24)-(28), and the values derived from our data analysis (coefficient $a_{2}$ in Table 1) for different fetch conditions.

It is shown that for the short-fetch condition, the values of $V_{S} / U_{10}$ derived from our data analysis are 


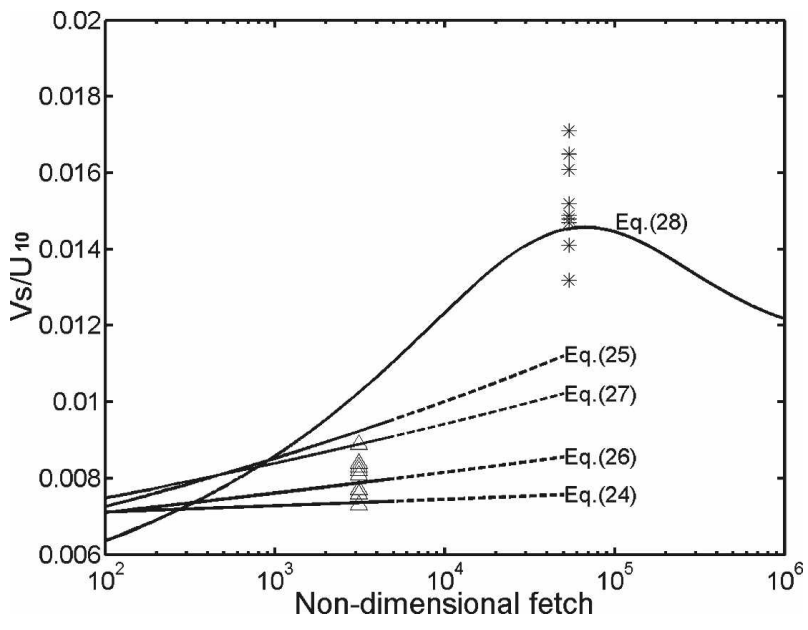

FIG. 13. The value of $V_{S} / U_{10}$ from empirical functions and from our data; values from (24)-(27) are shown as combined solid and dashed lines (dashed lines represent regions where these equations do not apply). For the transition zone, the CERC (1973) line [Eq. (28)] is shown (solid). The asterisks (long fetch) and triangles (short fetch) represent the value from our data analysis $\left(a_{2}\right.$ in Table 1).

within the range of values from empirical Eqs. (24)(27), with an average of $0.8 \%$; and for the transition region, the data are scattered around the value from (28) with an average of $1.5 \%$. Therefore, the result of our analysis for surface currents induced by Stokes drift is in agreement with that calculated from the empirical wave growth functions.

The above results suggest that, because of wave development, Stokes drift is more significant in generating surface currents under the long-fetch condition (transition region) than under the short-fetch condition, resulting in smaller $\phi$ values and larger $A_{C} / U_{10}$ values for the long-fetch condition.

In addition, the curve from (28) in Fig. 13 suggests that after the transition region, as nondimensional fetch continues to increase, the ratio $V_{S} / U_{10}$ decreases and is about $1.22 \%$ when the wave is fully developed. Data representing large nondimensional fetch conditions are needed to verify this trend.

\section{Conclusions}

The theoretical approach by Creamer et al. (1989) indicates that the Stokes drift component measured by HF radar should be derived from all waves in the spectrum that have wavelengths longer than that for the Bragg waves. The results of this paper indicate that the response of the ocean surface current to wind is a result of momentum transfer by both the wind stress and the Stokes mass transport. A quadratic law governs the former, and a linear law governs the latter. Therefore, the surface current is a superposition of components from both quadratic and linear relations. Under different nondimensional fetch conditions, resulting from differences in wave development, the significance of Stokes drift in generating the surface current varies, resulting in differences in both the ratio of surface current speed to wind speed $A_{C} / U_{10}$ and the angle $\phi$ between the surface current vector and the wind vector.

The correlation analysis of tidally filtered surface current data measured by HF radar with the local winds shows that, for most of the study area, wind dominates over other factors in generating surface currents (with correlation coefficient higher than 0.8). Current maps show that currents tend to follow the bathymetry contours in areas of high-bathymetry gradients. Ten grid points at the southern end where the filtered surface current is highly correlated with the filtered wind were chosen for the fetch analysis.

Two durations in the time series of wind represent the short- and long-fetch conditions. Wind data for these two durations are reasonably constant and strong. The ratio of surface current speed to wind speed $A_{C}$ ' $U_{10}$ is higher under the long-fetch condition (average value of $2.1 \%$ ) than under the short-fetch condition (average value of $1.5 \%$ ). In addition, the angle $\phi$ between the surface current and the wind is smaller under the long-fetch condition (average value of $14.4^{\circ}$ ) than under the short-fetch condition (average value of $\left.24.4^{\circ}\right)$.

Analysis of the data suggests that under the longfetch condition, Stokes drift dominates the surface current, while under the short-fetch condition, wind stress and Stokes drift are almost equally important in generating surface current. The ratios of Stokes drift to wind speed $V_{S} / U_{10}$ obtained from data analysis (coefficient $a_{2}$ ) are shown to agree well with the results calculated from empirical wave growth functions. The long-fetch condition belongs to the transition region in the wave growth regime, while the short-fetch condition belongs to the region with a high wave growth rate. Results show that the value of $V_{S} / U_{10}$ is around $1.5 \%$ under the long-fetch condition and $0.8 \%$ under the short-fetch condition. The larger value of $V_{S} / U_{10}$ under the long- than the short-fetch condition accounts for the larger $A_{C} / U_{10}$ and the smaller $\phi$ observed. In contrast, analysis results for the ratio $V_{E} / U_{10}^{2}$, that is, $\sqrt{2} a_{1}$, are similar in the short- and long-fetch conditions, suggesting that sea state does not affect the wind stressgenerated current in a significant manner.

In the open sea, the wind fetch is often long, which is favorable for wave development. Hence, the Stokes drift is expected to dominate the surface drift in the 
open ocean. This explains why in the open sea, the linear relation between the surface current and the wind dominates over the quadratic relation, as found by Kirwan et al. (1979), and the angle between the current and wind is always smaller than the $45^{\circ}$ that Ekman predicted (Madsen 1977). However, for areas under short fetch in the wave growth regime, the quadratic law for Ekman-type currents and the linear law for Stokes drift are about equally important in generating surface currents. These results imply that in the surface current prediction and 3D numerical modeling, varying the relation between current response and the wind according to different fetch condition will improve the outcomes.

This is an early result from 1 month of data in which only two periods satisfied the condition of constant wind direction at reasonably high, constant wind speed. Comprehensive data of surface currents and wind representing various nondimensional fetch conditions are needed to study in detail the variation of $\phi$ (the angle between the responding surface current and the wind) and $A_{C} / U_{10}$ (the ratio of surface current speed to wind speed) with fetch. It is also worth noting that no wave information was available in our study; otherwise, Stokes drift would have been derived independently from measured wave data. In the future, a more complete quantitative assessment of these ideas using measured wave directional spectra should be carried out. This work provides some insight into the physics of the momentum transfer from air to sea and shows that HF radar measurements of surface currents include the effect of Stokes drift. It demonstrates the value of HF ocean surface radar technology for carrying out surface current studies.

Acknowledgments. This work was supported by Australian Research Council SPIRT Grant C00002491. This work was carried out while Y. M. was a recipient of a Ph.D scholarship jointly sponsored by China Scholarship Council and James Cook University. The wind data were provided by the Australian Bureau of Meteorology. We wish to thank the Editor Dr. J. A. Smith for drawing our attention to Creamer et al. (1989). Valuable comments from the anonymous reviewers are also acknowledged.

\section{REFERENCES}

Bretschneider, C. L., 1952a: Revised wave forecasting relationships. Proc. Second Conf. on Coastal Engineering, ASCE, Council on Wave Research.

_ 1952b: The generation and decay of wind waves in deep water. Trans. Amer. Geophys. Union, 33, 381-389.

Bye, J. A. T., 1967: The wave drift current. J. Mar. Res., 25, 95102.
CERC, 1973: Shore protection manual. U.S. Army Coastal Engineering Research Centre, Vol. 1, 35, 46.

Chapron, B., F. Collard, and F. Ardhuin, 2005: Direct measurements of ocean surface velocity from space: Interpretation and validation. J. Geophys. Res., 110, C07008, doi:10.1029/ 2004JC002809.

Creamer, D. B., F. Henyey, R. Schult, and J. Wright, 1989: Improved linear representation of ocean surface waves. J. Fluid Mech., 205, 135-161.

Dobson, F., W. Perrie, and B. Toulany, 1989: On the deep-water fetch laws for wind-generated surface gravity waves. Atmos.Ocean, 27, 210-236.

Donelan, M. A., J. Hamilton, and W. H. Hui, 1985: Directional spectra of wind generated waves. Philos. Trans. Roy. Soc. London, 315A, 509-562.

Garratt, J. R., 1992: The Atmospheric Boundary Layer. Cambridge University Press, $316 \mathrm{pp}$.

Graber, H. C., and B. K. Haus, 1997: HF radar comparisons with moored estimates of current speed and direction: Expected differences and implications. J. Geophys. Res., 102 (C8), $18749-18766$

Gremes-Cordero, S., B. Haus, and H. Graber, 2003: Determination of wind-driven coastal currents from local weather station. Geophys. Res. Abstracts, 5, 751.

Hasselmann, K., and Coauthors, 1973: Measurements of windwave growth and swell decay during the Joint North Sea Wave Project (JONSWAP). Dtsch. Hydrogr. Z., 8A (Suppl.) (12), 95

Huang, N. E., 1979: On surface drift current in the ocean. J. Fluid Mech., 91, 191-208.

Janssen, J. A. M., 1997: Does wind stress depend on sea-state or not? A statistical error analysis of HEXMAX data. Bound. Layer Meteor., 83, 479-503.

Janssen, P., 2004: The Interaction of Ocean Waves and Wind. Cambridge University Press, $300 \mathrm{pp}$.

Kahma, K. K., 1981: A study of the growth of the wave spectrum with fetch. J. Phys. Oceanogr., 11, 1503-1515.

, and C. J. Calkoen, 1992: Reconciling discrepancies in the observed growth of wind-generated waves. J. Phys. Oceanogr., 22, 1389-1405.

Kirwan, A. D., Jr., G. McNally, S. Pazan, and R. Wert, 1979: Analysis of surface current response to wind. J. Phys. Oceanogr., 9, 401-412.

LeBlond, P. H., and L. A. Mysak, 1978: Waves in the Ocean. Elsevier, 602 pp.

Lewis, D. M., and S. E. Belcher, 2003: Time-dependent, coupled Ekman boundary layer solutions incorporating Stokes drift. Dyn. Atmos. Oceans, 37, 313-351.

Madsen, O. S., 1977: A realistic model of the wind-induced Ekman boundary layer. J. Phys. Oceanogr., 7, 248-255.

Mao, Y., M. L. Heron, and P. Ridd, 2007: Empirical modelling of surface currents for maritime operations. Proc. Coasts and Ports Conf. 2007, Melbourne, Australia, Maunsell AECOM, CD-ROM.

Paduan, J. D. and I. Shulman, 2004: HF radar data assimilation in the Monterey Bay area. J. Geophys. Res., 109, C07S09, doi:10.1029/2003JC001949.

Pierson, W. J., and L. Moskowitz, 1964: A proposed spectral form for fully developed wind seas based on similarity theory of S. A. Kitaigorodskii. J. Geophys. Res., 69, 5181-5190.

Polton, J. A., D. M. Lewis, and S. E. Belcher, 2005: The role of wave-induced Coriolis-Stokes forcing on the wind-driven mixed layer. J. Phys. Oceanogr., 35, 444-457. 
Stewart, R. H., 2005: Response of the upper ocean to winds. Introduction to Physical Oceanography, Texas A\&M University, 133-138. [Available online at http://oceanworld.tamu.edu/resources/ocng_textbook/contents.html.]

— currents. Deep-Sea Res., 21, 1039-1049.

Sverdrup, H. V., and W. H. Munk, 1944: Wind waves and swell: Principles in forecasting. Hydrographic Office, U.S. Navy, Misc. 11, 275.

_ 1946: Empirical and theoretical relations between wind, sea and swell. Trans. Amer. Geophys. Union, 27, 823-827.

Ullman, D. S., J. O'Donnell, J. Kohut, T. Fake, and A. Allen, 2006: Trajectory prediction using HF radar surface currents: Monte Carlo simulations of prediction uncertainties. J. Geophys. Res., 111, C12005, doi:10.1029/2006JC003715.
Wiegel, R. L., 1964: Oceanographical Engineering. Prentice Hall, $532 \mathrm{pp}$.

Wu, J., 1980: Wind-stress coefficients over sea-surface near neutral conditions-A revisit. J. Phys. Oceanogr., 10, 727-740. , 1983: Sea-surface drift currents induced by wind and waves. J. Phys. Oceanogr., 13, 1441-1451.

Yelland, M., and P. K. Taylor, 1996: Wind stress measurements from the open ocean. J. Phys. Oceanogr., 26, 541-558.

, B. I. Moat, P. K. Taylor, R. W. Pascal, J. Hutchings, and V. C. Cornell, 1998: Wind stress measurements from the open ocean corrected for airflow distortion by the ship. $J$. Phys. Oceanogr., 28, 1511-1526.

Young, I. R., 1999: Wind Generated Ocean Waves. Elsevier, 288 pp. 